\title{
Chapter 15 \\ Collective Learning and Institutional \\ Collective Action in Fragmented \\ Governance
}

\author{
Serena Y. Kim, William L. Swann, and Richard C. Feiock
}

Fragmentation of authority presents opportunities and challenges for governance. Multiple and/or overlapping political boundaries and jurisdictions can benefit governments by expanding citizen choice, increasing policy experimentation and knowledge diffusion, and reducing public expenditures (Andersson \& Ostrom, 2008; McGinnis, 1999; Ostrom, Tiebout, \& Warren, 1961; Schneider, 1986). However, fragmentation and lack of integration also produces externalities, or spillovers affecting third parties, that exacerbate institutional collective action (ICA) dilemmas, creating situations where authorities' particularistic incentives are misaligned with collective interests (Feiock, 2009, 2013; Swann \& Kim, 2018). For instance, in the context of air quality management, all governments in a fragmented region benefit from reduced air pollution, but each government has an incentive to free-ride and not contribute to the costs of achieving cleaner air.

ICA dilemmas hinder service delivery and common pool resource protection, and lead to fiscal problems and unsustainable outcomes (Hendrick, Jimenez, \& Lal, 2011; Jimenez, 2014). Thus, finding ways for governments to overcome ICA dilemmas is important for policymakers and researchers. The ICA framework (Feiock, 2007, 2013) is a valuable analytical lens for understanding how governments use integrative mechanisms to overcome barriers to collective action and promote collaborative governance. The ICA empirical literature has explored the structural, social, political, and economic factors shaping collaborations (Andrew \& Carr, 2013; Berardo \& Scholz, 2010; Feiock \& Scholz, 2010; Feiock, Steinacker, \& Park, 2009; Gerber, Henry, \& Lubell, 2013; LeRoux, Brandenburger, \& Pandey, 2010),

\footnotetext{
S. Y. Kim · W. L. Swann

School of Public Affairs, University of Colorado Denver, Denver, CO, USA

e-mail: serena.kim@ucdenver.edu; william.swann@ucdenver.edu

R. C. Feiock $(\bowtie)$

Askew School of Public Administration and Policy, Florida State University,

Tallahassee, FL, USA

e-mail: rfeiock@fsu.edu
}

J. Glückler et al. (eds.), Knowledge for Governance, Knowledge and Space 15, 
but little attention has been given to the role of learning in ICA dilemmas. Although learning is implicitly assumed to be a critical mechanism through which governments resolve ICA dilemmas, prior research has not developed a theory to articulate how this process may work.

The importance of learning is underscored in multiple literatures, including policy diffusion (Berry \& Berry, 1999; Shipan \& Volden, 2008), institutional change (Ostrom, 1990, 2005), advocacy coalitions (Sabatier, 1988), and policy learning (Dunlop \& Radaelli, 2018; Tamtik, 2016). Organizational theorists have also long considered how learning facilitates improved decision-making, practices, and performance (Argyris, 2003; Argyris \& Schön, 1978; Cohen \& Levinthal, 1990; March \& Olsen, 1995; Senge, 1990). More recently, researchers have paid attention to learning in collaborative governance, as collaborators face increased uncertainty and complexity (Crona \& Parker, 2012), but the relationship between learning and collaboration is complex. Interorganizational collaboration is thought to enhance collective learning processes and their cognitive and behavioral products (Gerlak \& Heikkila, 2011; Hartley \& Benington, 2006; Powell, 1998; Powell, Koput, \& SmithDoerr, 1996). However, learning is also believed to be a key facilitator of collaboration, social networking, and institutional change (Ansell, Lundin, \& Öberg, 2017; Koontz, Gupta, Mudliar, \& Ranjan, 2015).

To unpack this relationship, we posit a dynamic, iterative process through which collaboration leads to collective learning, which can subsequently enable governments to share and expand knowledge to better overcome ICA dilemmas in the future, or exacerbate such dilemmas if actors collectively learn to be more opportunistic. This iterative relationship lends itself to theories of collaborative governance evolution in that governments with little or no history of collaboration begin by solving smaller, "first-order" coordination problems of information exchange before taking on larger, "second-order" cooperation problems (Feiock \& Scholz, 2010) such as formalizing collaborative institutions. Although the ICA literature implies a logical connection between collaboration and learning (Hawkins, Krause, Feiock, \& Curley, 2017; Swann, 2017; Zeemering, 2019), extant scholarship has yet to tease out the explicit roles and implications for learning within ICA scenarios.

In this chapter, we examine the role of collective learning in employing alternative integrative mechanisms for overcoming ICA dilemmas. We ask: How does experience in collective action affect collective learning, and subsequently, how does it influence the ability of governments to overcome future barriers to collaboration? Surveying the extant literature and utilizing illustrative examples, we derive propositions for how collaborative governance may affect collective learning, and how collective learning may in turn enable governments to resolve future collaboration problems such as resource sharing, large-scale organizational reforms, and wicked policy problems.

In the next section, we review the ICA framework, discussing the implications of its empirical research for knowledge governance. We then define collective learning and describe how it relates to collaborative governance. Next, we advance propositions for the relationship between collective learning and integrative mechanisms for overcoming ICA dilemmas. We conclude by discussing the implications of knowledge governance for practice and future research. 


\section{ICA Foundations, Components, and Empirical Applications}

The ICA framework offers an institutional explanation for the emergence and durability of collective action among public authorities such as municipalities, public agencies, public service organizations, or national governments. Over the decade, many scholars have applied this framework to explain efforts to mitigate ICA dilemmas and improve collaborative governance. This section describes ICA's intellectual foundations, components, and applications to knowledge governance.

\section{Theoretical Foundations}

ICA proponents draw on elements of five theoretical traditions to explain the emergence and durability of collaborative governance. ICA is first informed by the collective action literature, whose authors hold that individuals' incentives may or may not align with collective interests, depending on the nature of the good and contextual governing rules (Olson, 1965; Ostrom, 2005). For example, Ostrom (1990) demonstrates how principals voluntarily govern themselves to obtain joint benefits and ensure the sustainable use of natural resources in the face of individual incentives to behave opportunistically. ICA assumes that policy actors can design and cultivate institutions based on trust, reciprocity, and mutuality to overcome collective action problems through means other than regulation or privatization (cf. Glückler, Suddaby, \& Lenz, 2018).

Second, ICA proponents draw from local public economies (LPEs) researchers (McGinnis, 1999; Ostrom et al., 1961), who posit that polycentricity, or "having multiple governing authorities at differing scales rather than a monocentric unit" (Ostrom, 2010, p. 552), can expand citizen choice, facilitate self-governance, and produce some public services more efficiently. However, polycentricity yields spillovers, in the form of positive and negative externalities that create collective action dilemmas, such as in air quality management and environmental policy. Feiock and Scholz (2010) classify these dilemmas as problems of "coordination" and "cooperation." The former relates to information asymmetries and the inability of actors to identify joint opportunities; the latter involves how to incentivize actors to work collectively and avoid opportunistic behavior. For example, resolving a coordination problem like information asymmetry might entail joint fact finding about air pollution sources and effects, whereas overcoming a cooperation problem, such as resource sharing or governmental reforms for climate protection, would require building trust and shared norms and values.

Third, ICA proponents consider how transaction costs are associated with obtaining information, negotiating and enforcing agreements, and aligning actors' values, preferences, and incentives (Feiock, 2007; Williamson, 1991). In the context of ICA situations, Feiock (2013) highlights two dimensions of transaction costs: autonomy and decision-making costs. ICA assumes that such costs increase as decisions 
become more hierarchically and/or externally imposed and deviate from local preferences. For instance, as air quality policies emanate from increasingly higher levels of government, local authorities have increasingly less discretion in their implementation and thus incur higher autonomy costs.

Fourth, ICA incorporates social network theories to explain how social capitalor the shared social resources (e.g., trust, reciprocity, and social structures) that can lead to collective action-reduces the likelihood of opportunistic behavior and lower barriers to collaboration (Burt, 1992; Coleman, 1988; Putnam, Leonardi, \& Nonetti, 1993). ICA assumes that increasing strong and weak network ties among actors will enhance the emergence and durability of collaborations. For example, city governments with weak ties bridging them to other actors and networks may have more information available to innovate and implement air quality policies, but cities with strong, bonding ties built on reciprocity, trust, and shared norms would be more likely to commit to improving air quality because they are confident their partners will live up to agreements.

Finally, ICA researchers draw on policy tools (Salamon, 2002) and political markets (Feiock, Lubell, \& Lee, 2014) to understand the interplay between government policy suppliers and constituent group policy demanders. ICA assumes policy choice and design are a function of political bargaining and negotiation between governmental officials and affected constituencies. In air quality management, this would imply that constituencies favoring environmental protection versus development would vie for the attention and favorable treatment of policymakers by providing their political support.

\section{Integrative Mechanisms, Transaction Costs, and Collaboration Risk}

Collaborative arrangements to overcome ICA dilemmas take a number of distinct forms. Feiock (2013) proposes a taxonomy of 12 generic integrative mechanisms, ranging from informal networks, where local actors preserve their autonomy and rely on trust and reciprocity to develop cooperative agreements, to centrally imposed authority, where consolidated governments are large enough to internalize policy spillovers and achieve economies of scale but at the expense of localized autonomy and policy variation. Figure 15.1 displays these mechanisms.

With the ICA framework, researchers posit that authorities can better link the integrative mechanism to the ICA dilemma by matching the scale and coerciveness of the integrative mechanism to the scale and nature of the policy problem. For instance, transportation planning in the United States is often delegated to regional authorities, such as metropolitan planning organizations (MPOs), to avoid particularistic decisions and better coordinate across jurisdictions, whereas informal networks have been often used for environmental management in areas like watersheds 


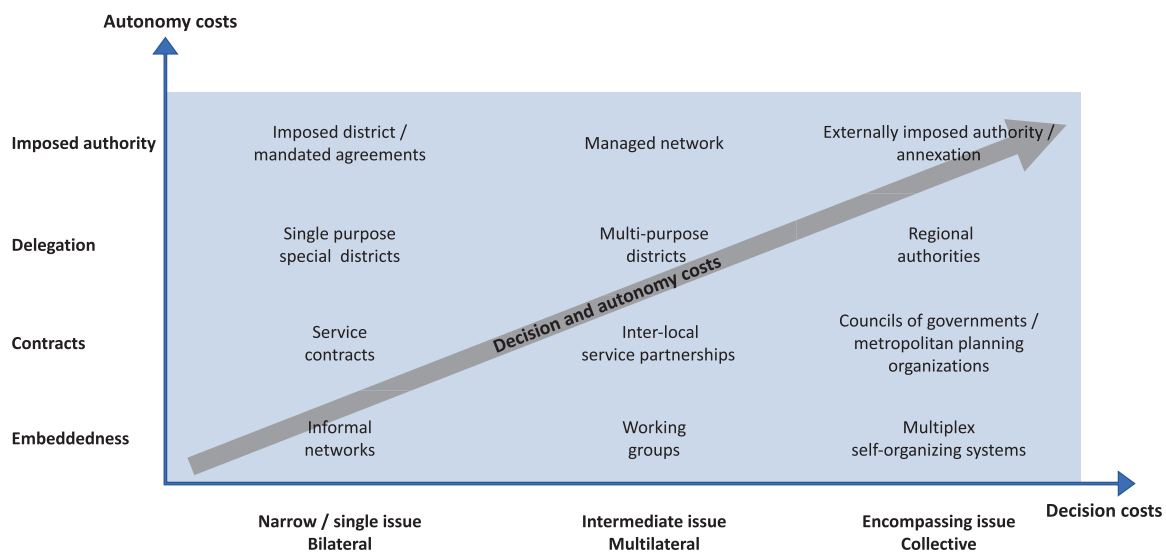

Fig. 15.1 Integrative mechanisms for overcoming ICA dilemmas. Adapted from R. C. Feiock (2013, p. 404). Copyright 2013 by John Wiley \& Sons, Inc. Adapted with permission

that span boundaries and involve numerous, diffuse, and heterogenous resource users (Scholz, Berardo, \& Kile, 2008).

Employing an integrative mechanism can resolve a collective action problem, but it imposes varying levels of transaction costs. Figure 15.1 illustrates how decision-making and autonomy costs relate to integrative mechanisms for institutional collective action (Feiock, 2013). The horizontal dimension captures the level of scope and complexity in collaboration, ranging from single issues on a bilateral scale to encompassing issues on a multilateral scale. The vertical dimension indicates the four levels of authority for collaborative arrangements: social embeddedness, contracts, delegation, and imposed authority. The diagonal dimension shows how autonomy and decision-making costs increase as issue complexity rises and authority becomes centralized. ICA proponents assume the preferred integrative mechanism overcomes the ICA dilemma by imposing the least costs and affording the most autonomy.

"Collaboration risk," or actors' perception of the likelihood that collaborative efforts will fail, is a key determinant of the integrative mechanism choice (Feiock, 2013). In theory, more authoritative and encompassing mechanisms will be necessary as collaboration risk increases. Although transaction costs are a function of the integrative mechanism choice, collaboration risks reflect actors' ex-ante subjective assessment of collaboration success or failure. Following Maser (1998), three types of collaboration risks are defined: Coordination risk refers to the inability to reconcile mutually beneficial opportunities; division risk concerns the difficulty of agreeing on the distribution of collaborative gains and costs; and defection risk is the likelihood that participants will not comply with a cooperative agreement (Feiock, 2013).

Collaboration risk emerges from the "collaboration situation," which consists of the (1) "nature of the problem" (e.g., coordination or cooperation problems, minimizing common pool resource problems, or internalizing externalities); (2) "actor 


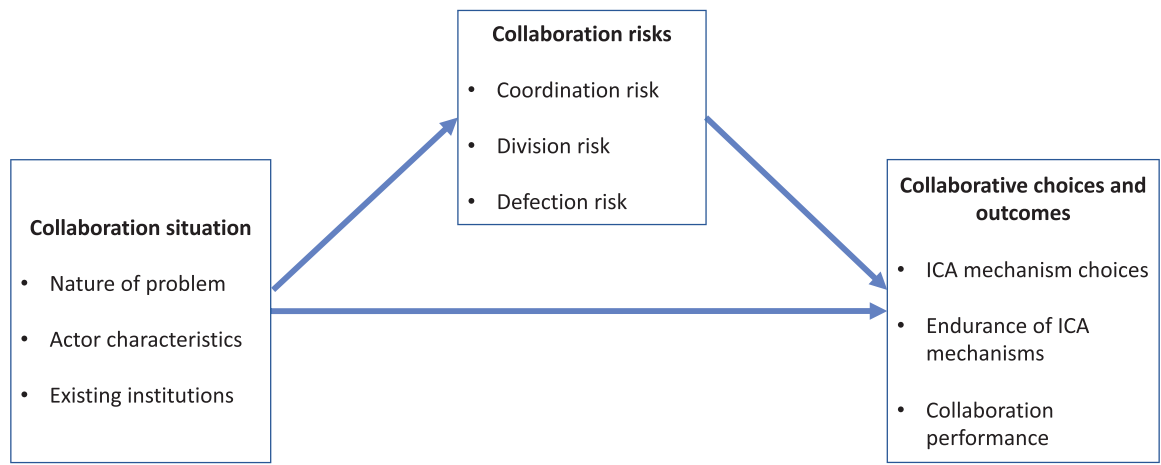

Fig. 15.2 Linkages between collaboration situation, risks, and choices and outcomes. Source: Design by authors

characteristics" (e.g., stakeholder preferences, interests, political dispositions, and resource asymmetries); and (3) "existing institutions" (e.g., rules, norms, shared values, and structural characteristics, such as actors' individual or organizational networks, influencing how they have interacted in the past). In other words, collaboration risk is conditioned by the nature of the problem, actor characteristics, and existing institutions, which in turn influences the integrative mechanism choice.

Figure 15.2 illustrates this relationship, that is, how the collaboration situation relates to collective outcomes and integrative mechanism choices. Many of the ICA empirical literature's authors have examined these relationships, mostly the direct effect of the collaboration situation on collaboration choices and outcomes. In this chapter, we add a fourth component — collective learning — to this model and argue that it has the potential to reduce collaboration risks and lead to more self-organizing integrative mechanisms, such as informal networks, that impose fewer decisionmaking and autonomy costs. To begin developing this theory, we first need to consider how the ICA literature informs knowledge governance.

\section{Empirical Applications for Knowledge Governance}

Although both are integral to learning, information and knowledge are different. Generally, information consists of facts about something or someone, but knowledge is gained through experience, education, and the analysis of information. In this sense, learning relates more to knowledge than information, but having (good) information should facilitate learning.

Obtaining information about collaboration can be costly but is essential (Feiock et al., 2009). So far, researchers have focused on how the informal networking of individual policymakers influences decisions to formally collaborate interorganizationally (Andrew \& Carr, 2013; Hawkins, Hu, \& Feiock, 2016; LeRoux et al., 2010). They claim that informal networking enables actors to build trust and shared 
understanding through dialogue and information exchange, which can lead to formal interorganizational collaborations. Although not explicitly mentioned, learning could be a key mechanism through which informal networking influences these partnerships, as information sharing enables actors to learn about similar projects in other jurisdictions and serve as brokers in collaboratives (Spekkink \& Boons, 2016).

Information is not only a facilitator of collaboration but can also be obtained, assimilated, and disseminated through collaboration. ICA researchers investigating estuary policy networks, for example, suggest that organizational actors seek out partnerships with popular, well connected organizations to obtain informational resources (Berardo \& Scholz, 2010; Scholz et al., 2008). Actors use network ties to obtain more information about other actors' credibility and to increase their technical knowledge of the policy area.

Some collaboratives, however, may inhibit information acquisition, especially over time. Governments tend to collaborate with other governments that are politically, demographically, and geographically similar (Gerber et al., 2013; Lee, 2016). Although homophily-based collaboration may be beneficial for lowering initial barriers like lack of trust, such collaboration may not be conducive to generating new information, because similar actors in the same networks likely have similar information. Thus, actors may be better off collaborating with heterogeneous partners to acquire new information (Burt, 1992).

Acquiring knowledge goes a step further than gathering information and requires combining information with analysis and experience. One way actors build knowledge in collaboration is through focusing on intermediate outcomes or "small wins" (Ansell \& Gash, 2008; Huxham \& Vangen, 2005). This approach is similar to what Feiock and Scholz (2010) discuss in terms of addressing first-order dilemmas such as coordinating joint efforts for planning and fact finding, before tackling secondorder dilemmas such as cooperating in resource exchanges. This evolution of collaboration lends itself to collective learning: Actors build a foundation for learning as they gather information, resolve coordination issues, and achieve intermediate outcomes, and build knowledge incrementally through the cooperative application of information towards collective aims. In the following section, we draw on collective learning research to begin building a theory to explain the relation between collective learning and institutional collective action.

\section{Learning and Collective Action}

In recent years, scholars have emphasized the importance of learning in collective action (Ansell \& Gash, 2008; Gerlak \& Heikkila, 2011; Heikkila \& Gerlak, 2013; Koontz et al., 2015; Newig, Günther, \& Pahl-Wostl, 2010). Although they have defined learning in numerous ways, scholars generally agree that it involves both cognitive and behavioral changes. From this perspective, it is insufficient for one to learn by experiencing changes in the brain unless such changes are acted upon (Argyris, 2003). However, attributing policy change to learning has proved difficult 
(Heikkila \& Gerlak, 2013), because policy change can occur for many reasons such as mimicry and imitation, bargaining and negotiation, and exogenous influences such as economic, political, and cultural shifts, which may or may not involve learning.

Learning occurs at both the individual and collective level. Although individuals can experience cognitive and behavioral changes, these changes do not necessarily transfer to the group. Collective learning involves alteration to social structures, which are comprised of institutional (i.e., formal and informal rules, norms, and expectations) and relational (i.e., social networks) components (Newig et al., 2010). However, the process through which individual learning transfers to the group, or vice versa, remains unclear.

One possible means is through "single- and double-loop learning," in which the former involves changes based on discrepancies between actions and goals, and the latter involves changes in goals based on shifts in values (Argyris, 2003; Newig et al., 2010). Single- and double-loop learning at either level may affect learning at the other. For example, after an executive learns from performance metrics that the achievement of organizational goals is unlikely (single-loop learning), the executive engages top management and staff in a discussion about new strategies, or whether these goals are the appropriate goals to achieve at the organizational level (doubleloop learning), and vice versa.

Learning may also transfer across levels through experiential learning, or learning from past experiences (March \& Olsen, 1995). Experiential learning leads to accumulation of habits, tradition, customs, and organizational routines at the group level. According to March and Olsen, experiential learning involves three processes: (1) variation in experience, (2) selection and inference from the experience, and (3) retained experience in the form of institutions or rules. Through these processes, new ideas brought into the system compete with one another in an existing institution, which fosters adaptation of behavior through the competition of ideas. In other words, ideas proven to be more successful are diffused through forms of instruction and exemplification. Researchers believe that this mutual interaction between new ideas and existing institutions leads to learning.

\section{Collective Learning Processes and Products in Governance}

Following Heikkila and Gerlak (2013), we define collective learning as involving (1) collective processes such as acquiring (i.e., collecting or receiving information), translating (i.e., interpreting or applying new information), and disseminating (i.e., transferring information across groups) knowledge, and (2) collective products such as cognitive and behavioral changes. Heikkila and Gerlak argue that the collective processes of knowledge acquisition, translation, and dissemination influence the emergence of collective products that we typically associate with policy learning: new ideas, strategies, rules, and policies.

The relationship between collective learning processes and products may not be unidirectional, as collective learning products could influence the processes or steps 
through which actors learn, and vice versa. Thus, we view collective learning as a dynamic, iterative, self-reinforcing process that strengthens actors' ability to adapt and learn further through improving processes. Through collective learning processes and products, actors develop their capacity to learn in more intelligent ways and generate and share greater knowledge over time. However, it is plausible that actors can also collectively learn to be more strategic and pursue their self-interests in collaboratives, which would lead them to guard knowledge and information from others.

Although learning occurs in all sectors, we focus on the role of collective learning in producing public value (Moore, 1995), viewing the processes of learningknowledge acquisition, sharing, translation, and adaptation-as courses of action that can cultivate mutual reciprocity and democratic values such as legitimacy and inclusivity. When it comes to learning products in governance, political and contextual knowledge about citizen preferences or building consensus are equally important as scientific and technological knowledge. Although researchers believe that these processes and products of collective learning are important for collaborative governance, extant scholarship lacks a theory for how they facilitate institutional collective action. We begin developing such a theory in the following section.

\section{Three Pathways Linking Collective Learning to Institutional Collective Action}

Figure 15.3 displays our conceptual model for how collective learning can lead to the resolution or perpetuation of ICA dilemmas and the improvement of collaborative governance. We posit three pathways linking collective learning to institutional collective action. In the first path, collaborative choices and outcomes affect collective learning: Actors either learn to be better collaborators, or more opportunistic and self-interested. "Path A" in Fig. 15.3 is informed by extant research suggesting collaboration enhances learning (Hartley \& Benington, 2006; Heikkila \& Gerlak, 2013; Leach, Weible, Vince, Siddiki, \& Calanni, 2013).

In the second path, collective learning directly mitigates collaboration risks and in turn alters the integrative mechanism choice (Path B in Fig. 15.3). Although we acknowledge actors can collectively learn to be more strategic and pursue their own particularistic interests, we assume greater knowledge about collaboration and more information about partners enable actors to better deal with collaboration problems, heterogeneous preferences, and weak institutions for collaboration, thus reducing collaboration risk.

In the third path, collective learning moderates the relation between the collaboration situation and risks (Path $\mathrm{C}$ in Fig. 15.3). That is, collective learning has greater impact in high-complexity ICA situations characterized by highly fragmented, specialized, and multifaceted contexts (e.g., global climate change or international epidemic prevention) than in low-complexity ICA situations (e.g., local waste management contracts). Our logic is that because we are treating the 


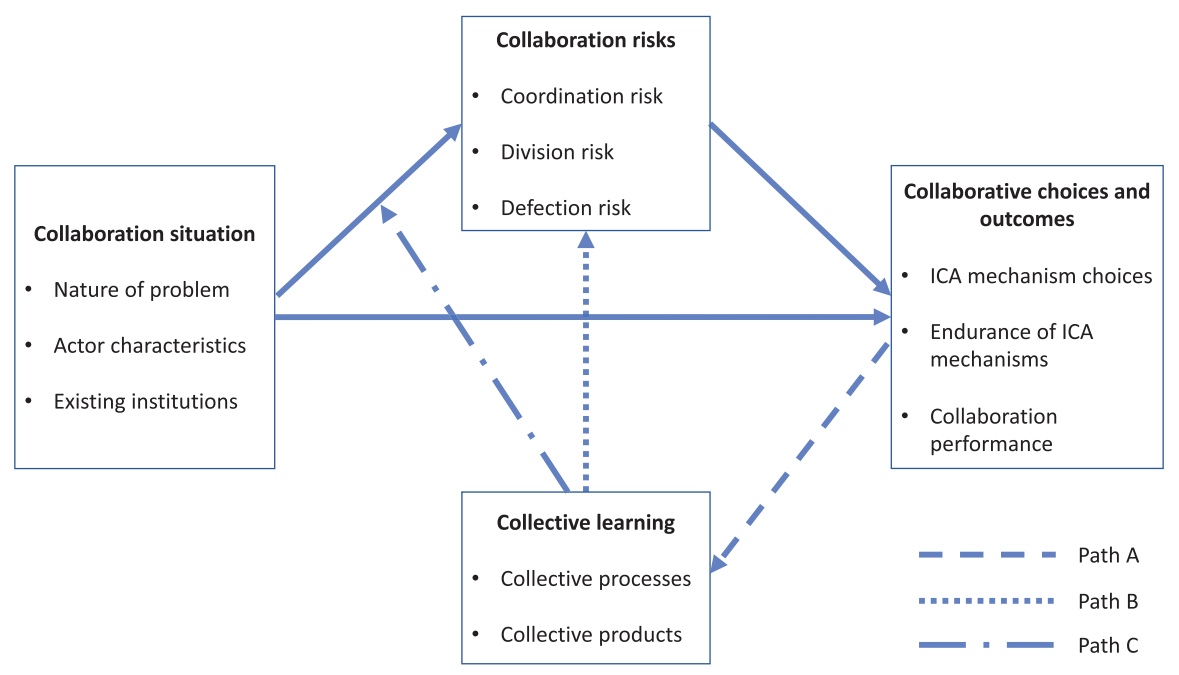

Fig. 15.3 Three pathways of collective learning in ICA situations. Source: Design by authors

collaboration situation as exogenous, collective learning has very little direct influence over the current situation or the complexity that authorities face, but rather affects the extent to which such complexity influences collaboration risks.

\section{Path A: Collaboration Choices and Outcomes Influencing Collective Learning}

In this section, we explore how collaboration choices and outcomes enhance collective learning (Path A in Fig. 15.3). Collaboration is critical for knowledge acquisition, diffusion, and development because learning often occurs through external opportunities and insights (Crona \& Parker, 2012; Powell, 1998). Collaboration has been found to help policy actors discover and assimilate new knowledge that is integral for learning in governance (Gerlak \& Heikkila, 2011; Hartley \& Benington, 2006; Leach et al., 2013). Our first claim is that collaboration delivers new knowledge to policy actors, which in turn facilitates learning and the ability to govern fragmented governments in the future. Below, we discuss how different integrative mechanisms may have differentiated effects on collective learning, and how social networking and other information technology advancements may influence such learning. 


\section{Integrative mechanism choices and collective learning}

Although collective learning is enhanced by collaboration, there may be trade-offs between different learning components (i.e., knowledge acquisition, translation, sharing, adaptation, and retainment). Research suggests that decentralized or polycentric collaboration is more conducive to knowledge generation, dissemination, and experimentation, but authoritative integrative mechanisms may be better for retaining knowledge through formalized rules (Gerlak \& Heikkila, 2011; Heikkila \& Gerlak, 2013; March \& Olsen, 1995). Thus, we posit that different integrative mechanisms (Fig. 15.1) have differentiated advantages for collective learning. Although voluntary, informal integrative mechanisms may offer advantages in information acquisition and knowledge creation (Willem \& Buelens, 2007), imposed or delegated integration, which entail greater hierarchy, may be more efficient in translating, adopting, and retaining knowledge (March, 1991; March \& Olsen, 1995). Likewise, more "managed networks" (i.e., led internally or externally by a single organization) could offer advantages in processing information in a more systematic and organized manner to maintain stability, but may inhibit the ability to adapt and discover new knowledge over time (Provan \& Kenis, 2008).

There are also benefits of assimilating diverse networks of actors to enhance collective learning. Although vertical integration of a learning system is conducive to coping with larger problems and reduces coordination and information-sharing costs, autonomous horizontal learning across multiple and overlapping jurisdictions fosters policy experiments, evaluation, and adaptation (Koontz et al., 2015). Thus, although researchers have acknowledged, for example, potential trade-offs in learning between exploration and exploitation (March, 1991), overlapping collaborative structures may provide some advantages for collective learning. In the ICA context, self-organizing and more authoritative mechanisms could complement each other, especially in complex situations. For example, empirical research on climate change adaptation finds the need for both authoritative, top-down and self-organizing, bottom-up collaborative networks in the production and sharing of knowledge (Homsy \& Warner, 2013). Interactive, two-way collaborative learning and localized networks involving diverse stakeholders are essential for addressing complex problems (Weber \& Khademian, 2008).

Proposition 1: Self-organizing integrative mechanisms are better for acquiring and disseminating new information, but more authoritative mechanisms are better for processing and retaining knowledge.

Proposition 2: Combining integrative mechanisms (e.g., self-organizing with more authoritative mechanisms) will improve collective learning and enable authorities to take on more complex, second-order ICA cooperation problems in the future. 


\section{Social networking, technology, and collective learning}

Social networking and other information technology advancements reduce the cognitive distance between partners and facilitate communication and collaboration opportunities, thereby potentially enhancing shared understanding and collective learning. For example, social networking services, webinars, video conferencing, and cloud services can enhance governments' ability to absorb information and foster the shared norms and understanding traditionally cultivated by in-person dialogue. Mutual understanding and shared values are believed to emerge from frequent communication and social interactions. For example, policy dialogue in informal networks helps actors build trust and norms of reciprocity, enabling them to overcome ICA dilemmas and formalize interorganizational collaborations (Andrew \& Carr, 2013; Hawkins et al., 2016; LeRoux et al., 2010). Social networking services can complement or, in some instances, replace the in-person, face-toface dialogue that has enabled authorities to develop collaboratives.

Other information technology such as databases, cloud computing, and shared servers could also mitigate challenges in collective action for knowledge governance (Heikkila \& Gerlak, 2013). Knowledge acquisition and dissemination can be facilitated through a unified information-sharing platform, allowing collaborative partners to assemble, standardize, simplify, and update information. These information-technology management tools enable organizations to better combine knowledge discovery and retention practices, and thereby manage information in a more synergistic way. For example, constructing shared servers where actors collectively encode, store, and retrieve information could enhance knowledge discovery, sharing, and retention in governance.

Whether through in-person conversation or electronic-based dialogue, collaboratives require actors to build trust, mutuality, and shared understanding through dialogue (Ansell \& Gash, 2008). Current technology has expanded opportunities for dialogue, with the help of web-based information sharing and video conferencing platforms. With these advancements, it should be easier to find potential collaborators with similar interests and arrange meetings, even though actors are not geographically close. We argue that these increased opportunities for dialogue will lead to more collaboration opportunities and better outcomes, which in turn enhance collective learning and the ability to tackle higher-order cooperation problems as collaboratives mature.

Proposition 3: Social networking services and advances in information technology management enhance collaboration by providing capacity and facilitating dialogue, which in turn promotes collective learning and the ability to address more complex, second-order cooperation problems in the future. 


\section{Path B: Collective Learning Influencing Integrative Mechanisms Through Collaboration Risk Mitigation}

Integrative mechanism choices (Fig. 15.1) are shaped by the collaboration risks of coordination, division, and defection (Carr, Hawkins, \& Westberg, 2017; Feiock, 2013). But collective learning could mitigate these risks by providing actors with greater knowledge about other actors, joint benefits (and costs), and collaborative opportunities. Thus, our second claim is that integrative mechanism choices (and presumably their endurance and outcomes) can be directly altered by mitigating collaboration risks through collective learning (Path B in Fig. 15.3). In other words, the relationship between collective learning and integrative mechanism choices is mediated by collaboration risk mitigation. Below, we discuss how collective learning relates to the three types of collaboration risks.

\section{Coordination risk}

Coordination risk emerges as participants conflict over cooperative goals or the participants' responsibilities, and is inherent in situations where actors identify the benefits of joint activity but fail to collaborate due to information incompleteness (Carr et al., 2017; Feiock, 2013). For example, interlocal collaboration for economic development may be hindered as actors fail to reach consensus because of lack of information about future economic conditions and the high uncertainty of economic ventures (Hawkins, 2009).

Coordination risk may be strongly related to resource discrepancies. For example, when affluent governments are able to implement proactive collaborative policies to protect wetlands and wildlife habitats (see Porter \& Salvesen, 1995), neighboring impoverished governments may not have the same expertise and resources to take similar or complementary actions, which may exacerbate information sharing in ICA situations.

When coordination risk is high, lead network actors could also play a key role in mitigating such risk through collective learning. Researchers have widely identified knowledge sharing and information exchange as key facilitators of collaborative governance (Ansell \& Torfing, 2015; Lubell, Mewhirter, Berardo, \& Scholz, 2017; Shrestha, Berardo, \& Feiock, 2014), and lead agencies are more likely to facilitate learning by disseminating new information and knowledge across organizations (Gerlak \& Heikkila, 2011). Researchers have found that lead agencies help establish a common vision among participants in regional water management and allow for the development of norms and informal rules that are pivotal for learning (Conrad, 2015).

In addition, integrating different types of knowledge may also mitigate coordination risk (Lubell et al., 2017; Yang, 2017). For example, utilization of local knowledge (such as indigenous, traditional, or community knowledge) to make sense of scientific and political knowledge (i.e., understanding the interests of other actors) has been found to enhance the performance of interjurisdictional desertification 
prevention (Yang, 2017). From this perspective, we argue that utilizing different types of knowledge will help solve the conflicts over collaborative goals and reduce uncertainties associated with collaborative arrangements.

\section{Division risk}

Division risk arises when actors share general collaborative goals but are unable to agree on how to distribute the benefits and costs associated with joint activities. Division risk increases as a party to an agreement becomes relatively worse off. Here, we argue that collective learning - in the form of shared knowledge about partners' payoffs, interests, and needs-mitigates division risk.

Consider the North American Free Trade Agreement (NAFTA). Division risk could be mitigated by mutual knowledge about the social, economic, and political situations of partner countries. Let us assume, for example, that the enactment of NAFTA worsened conditions for Mexico's energy companies. This collaborative would suffer from high division risk, because Mexico could roll back the agreement under a new administration. However, NAFTA could mitigate such uncertainty through more accurate projections about expected benefits (or costs) (Zumbrun, Pérez, \& Harrup, 2018). This knowledge can empower Mexican officials to persuade domestic interest groups wary of NAFTA consequences and reduce their uncertainty about economic payoffs.

Research suggests that frequent interaction mitigates the problem of dividing collaborative benefits (Lubell et al., 2017), and informal networking in frequent regional meetings leads to greater formal interlocal collaboration (Tavares \& Feiock, 2017), minimizing the division risk associated with formal agreements (Hawkins et al., 2016). We posit that frequent informal interactions will help participants reach a consensus about how to divide the benefits and costs of collaborative arrangements, especially in the early stages of collaboratives.

Over time, the development of a strong history of collaboration and collective learning should have the most impact on reducing division risk. For example, Boer, and Bressers (2011) point out that interregional water governance in the Netherlands dates back to the thirteenth century, and this long history allow actors to better deal with uncertainty. Rather than controlling interregional collaboration for water governance from the top-down, which may result in decreased flexibility and autonomy, adaptive approaches based on mutual trust and a history of reciprocity have enabled participants in the Netherlands to more effectively adjust collective benefits and costs (Boer \& Bressers, 2011).

\section{Defection risk}

Defection risk emerges when actors renege or free-ride on an agreement or collective effort. Defection risk differs from coordination and division risks in that participants have conflicting interests (Feiock, 2013). That is, noncompliers achieve better 
outcomes by free-riding or reneging, but compilers end up worse off because they bear the full cost of providing the public good. In reality, it is extremely difficult to obtain complete information about partners' motivations and commitment to achieving collective goals. Thus, proponents of transaction cost economics (TCE) argue that it is necessary to align incentives and/or design effective monitoring mechanisms. But collective learning may mitigate the need for monitoring or, in the ICA context, more authoritative integrative mechanisms by building a better understanding of partners' motives and tendencies to engage in self-interested or cooperative behavior (Nooteboom, 2000).

Generally, more authoritative integrative mechanisms are required when defection risk is high (Feiock, 2013). In transportation planning, for example, when municipalities lack trustworthiness and the capacity to make credible commitments to a collective effort, regional authorities such as MPOs are more likely to utilize vertical, top-down integration to prevent opportunistic behavior among municipalities. But collective learning may shift the integrative mechanism choice from more authoritative to more self-organizing (Fig. 15.1), as actors begin to understand more about their partners' credibility and trustworthiness. For instance, governments that have contracted with a nonprofit for decades may not need stringent monitoring mechanisms because defection risk is low, and they can rely more on relational or informal contracting (Terman \& Feiock, 2016).

We summarize our arguments on how collective learning influences collaboration choices and outcomes through the mitigation of the three collaboration risks as follows:

Proposition 4: Collective learning directly reduces collaboration risks (i.e., coordination, division, and defection risks), thus increasing the likelihood of adopting more selforganizing integrative mechanisms for resolving ICA dilemmas in the future.

\section{Path C: Collective Learning Moderating the Collaboration Situation-Risk Linkage}

Our third claim is that collective learning has a greater impact in high-collaboration risk situations than in low-collaboration risk situations. In other words, collective learning moderates the relation between the collaboration situation and collaboration risks (Path $\mathrm{C}$ in Fig. 15.3). For example, learning about actors' needs and capacities, institutional differences, and political and economic environments is relatively more critical in complex, high-risk situations (e.g., global climate change mitigation, international drug trafficking, multinational disease prevention, etc.), than in relatively less complex, lower-risk situations. Table 15.1 summarizes this contrast between high- and low-risk ICA situations.

Feiock (2013) suggests that, to address real-world problems with integrative mechanisms, the sources of collaboration risk should be diagnosed. He divides the sources of collaboration risk into three categories: (i) the nature of the problem, (ii) 
Table 15.1 Low and High Collaboration Risk Situations

\begin{tabular}{lll}
\hline $\begin{array}{l}\text { Collaboration situation } \\
\text { (sources of collaboration } \\
\text { risk) }\end{array}$ & Low collaboration risk & High collaboration risk \\
\hline Nature of the problem & $\begin{array}{l}\text { Jurisdictions and authority are } \\
\text { less fragmented, more } \\
\text { centralized }\end{array}$ & $\begin{array}{l}\text { Jurisdictions and authority are } \\
\text { highly fragmented, more } \\
\text { decentralized }\end{array}$ \\
& $\begin{array}{l}\text { Issue is simple (first-order } \\
\text { coordination problem) } \\
\text { Coordination is sufficient (e.g., } \\
\text { information sharing, fact } \\
\text { finding, etc.) }\end{array}$ & $\begin{array}{l}\text { Issue is complex (second-order } \\
\text { cooperation problem) } \\
\text { Cooperation is required (e.g., } \\
\text { shared authority, institutional } \\
\text { reform, etc.) }\end{array}$ \\
& $\begin{array}{l}\text { Homogenous preferences } \\
\text { Reputations are well known } \\
\text { Actor preferences }\end{array}$ & $\begin{array}{l}\text { Heterogeneous preferences } \\
\text { Little is known about actors } \\
\text { Extlant history and }\end{array}$ \\
institutions of collaboration & $\begin{array}{l}\text { Little history and institutions of } \\
\text { collaboration }\end{array}$ \\
\hline
\end{tabular}

Note. Source: Design by authors

actors' preferences, and (iii) existing institutions. Each source adds to collaboration risks and relates to collective learning in a differentiated manner.

The nature of the problem lies in the specific type of ICA dilemma (e.g., minimizing air pollution in a region, managing the ecosystem of a watershed, etc.) and collaboration risk varies depending on the nature of the problem, that is, the more complex the problem, the higher the collaboration risk. Interlocal shared services for solid waste management, for example, generally entail lower collaboration risk than, say, international efforts to combat global drug trafficking (see Munsing \& Lamb, 2011). Although authority is fragmented in both cases, the latter issue is exponentially more complicated, as it involves more actors and has far more confounding variables at play (e.g., illegal labor markets, money laundering, macroeconomic conditions, etc.). In the public policy literature, these problems are typically described as more intractable or wicked. Logically, collaboratives to resolve these problems should thus involve greater risks. We argue that collective learning is more valuable in these high-risk situations because participants more strongly require knowledge and information sharing about the nature and characteristics of the problems. In high-risk situations, where other complex issues are related, and/or critical events are frequently happening, it is more vital for participants to learn the circumstances and history and to use this knowledge to adapt to fast-changing problems.

Actor preferences refer to the extent of social, economic, and political diversity or homogeneity among collaborating units (Feiock, 2013). Collaboration risk is higher when actor preferences are heterogenous and information about other actors is limited. As in the previous example, collaboration between two adjacent municipalities in solid waste management entails relatively lower collaboration risk than in an international drug enforcement network. Collective learning about other actors' behavior, capacity, and incentives is therefore more important when actor preferences are heterogenous, because actors have a greater need to develop a shared understanding of where their preferences diverge and align. 
Finally, existing institutions entail the rules, laws, and political, economic, and social circumstances embedded within the integrative (or collaborative) mechanism (cf. Glückler et al., 2018). Collaboration risk is lower when actors have effective collaborative institutions for resolving collective action problems. For instance, two local governments with a long history of working together will have lower collaboration risk than other local governments with little previous interaction. Collective learning and shared knowledge about other governments' institutions, such as rules, norms, and practices should be be more valuable for those municipalities with few existing institutions for collaboration. In a high-risk situation with little history of collaboration, there is a greater need to learn individual actors' roles, incentives, and future contributions in and for collaboratives. Actors will also have to learn what collaborating institutions will work and what must be done to sustain collaborative benefits. We summarize our arguments on how and why collective learning may have greater impact in high-collaboration risk situations than in low-collaboration risk situations as follows:

Proposition 5: The indirect or moderating effect of collective learning on collaboration risk is greater in high collaboration risk situations than in low collaboration risk situations.

\section{Concluding Thoughts}

Learning is important in all facets of society and is especially critical in governance, where the acquisition and dissemination of knowledge is often a core function (Willem \& Buelens, 2007). Fragmentation of authority can present significant barriers to knowledge sharing and collective learning. Thus, identifying how governments overcome barriers to sharing knowledge and collectively learning about collaboration is important. Combining theories of collective learning (Heikkila \& Gerlak, 2013) and institutional collective action (Feiock, 2013) is one avenue for enhancing our understanding of knowledge sharing in fragmented governance. This chapter has discussed how collaboration choices and outcomes can improve collective learning, which in turn lowers barriers to fostering better collaborative arrangements by mitigating collaboration risks. The model proposed in this chapter suggests multiple pathways and propositions to be tested in future research.

It is important to note why institutional collective action has significant implications for collective learning. Collective learning may not have an enduring influence unless such learning is institutionalized in organizations. That is, in order for the learning-collaboration feedback loop to work, collective learning should change how actors collaborate; they become either more cooperative or more self-interested through collaboration. In this way, the mutual reinforcement between learning and collaboration can enhance long-term institutional resiliency, or "the degree to which political institutions lessen the significance of crisis, turbulence, and challenges using technologies, networks, or policy coalitions for knowledge governance" (March \& Olsen, 1995, p. 184). More relevant knowledge acquired through 
"learning-by-doing" and "trial-and-error" helps build long-lasting, adaptive, and resilient institutions and enhances actors' ability to anticipate the future (Koontz et al., 2015). We expect that the more collaborative institutions are exposed to challenges, the better they can gauge what knowledge and information is valuable and worth absorbing and utilizing. Even if participants opt out of or fail in collaboration, the competition, conflicts, and difficulties in collective action can provide valuable insights, assuming actors are not encouraged to behave more opportunistically based on what they learn.

Our model also implies that governments may be able to more effectively utilize collective learning for collective action by acknowledging partners' heterogeneous experiences and ideas as sources of acquiring new information and knowledge; utilizing social networking services and information technology advancements for collaboration and collective learning; and understanding that collaboration must be developed over time, through multiple iterations. Actors in collaboratives will inevitably make mistakes, but better collaborators will learn from these mistakes and, in doing so, enhance their ability to collaborate in the future.

Although we have noted the many benefits of collective learning for collaborative governance, political institutions bear some inherent limitations. As March and Olsen (1995, p. 238) point out, political systems easily forget: Lessons that are not coded into rules, traditions, and standard operating procedures are lost through turnover and the passage of time. Conversely, political institutions remember some things too well or too poorly: Rules can take on their own justification and build beliefs that sustain them far beyond their original intent; institutional memories can be adulterated by self-interested desires, tactics, and reinterpretations of experiences. Moving forward, it is thus important to consider the context in which collective learning takes place and to be careful about generalizing across sectors or cultures.

Secondly, our model of collective learning in ICA situations (Fig. 15.3) assumes actors are learning to be more cooperative than self-interested and opportunistic. This is a big assumption, and actors could very likely learn to be more opportunistic and guarded in collaboratives, especially in the case of failures or dysfunctions. Empirically teasing out when actors learn to be cooperative and when they learn to be noncooperative is a key challenge for future research.

Finally, although many researchers over the decades have offered numerous and fruitful ways of measuring learning in social contexts, there is much work to be done. The literature appears to be moving away from convenient yet less-thandesirable proxy measures of learning, such as policy diffusion and change, performance improvements, strategic redirections, and so forth, and paving the way through process-based and behavioral approaches to understanding collective learning (Heikkila \& Gerlak, 2013). This is a step in the right direction and greater experimentation in approaches will likely lead to better measures of collective learning. 


\section{References}

Andersson, K. P., \& Ostrom, E. (2008). Analyzing decentralized resource regimes from a polycentric perspective. Policy Sciences, 41(1), 71-93. https://doi.org/10.1007/s11077-007-9055-6

Andrew, S. A., \& Carr, J. B. (2013). Mitigating uncertainty and risk in planning for regional preparedness: The role of bonding and bridging relationships. Urban Studies, 50, 709-724. https:// doi.org/10.1177/0042098012455718

Ansell, C., \& Gash, A. (2008). Collaborative governance in theory and practice. Journal of Public Administration Research and Theory, 18, 543-571. https://doi.org/10.1093/jopart/mum032

Ansell, C., Lundin, M., \& Öberg, P. O. (2017). Learning networks among Swedish municipalities: Is Sweden a small world? In J. Glückler, E. Lazega, \& I. Hammer (Eds.), Knowledge and networks (pp. 315-336). Knowledge and Space: Vol. 11. Cham: Springer. https://doi. org/10.1007/978-3-319-45023-0

Ansell, C., \& Torfing, J. (2015). How does collaborative governance scale? Policy \& Politics, 43, 315-329. https://doi.org/10.1332/030557315X14353344872935

Argyris, C. (2003). A life full of learning. Organization Studies, 24, 1178-1192. https://doi. org/10.1177/01708406030247009

Argyris, C., \& Schön, D. A. (1978). Organizational learning: A theory of action perspective. Reading: Addison-Wesley.

Berardo, R., \& Scholz, J. T. (2010). Self-organizing policy networks: Risk, partner selection, and cooperation in estuaries. American Journal of Political Science, 54, 632-649. https://doi. org/10.1111/j.1540-5907.2010.00451.x

Berry, F. S., \& Berry, W. D. (1999). Innovation and diffusion models in policy research. In P. A. Sabatier (Ed.), Theories of the policy process (pp. 169-200). Boulder: Westview.

Boer, C. L., \& Bressers, J. T. A. (2011). Complex and dynamic implementation processes: The renaturalization of the Dutch Regge River. Enschede, The Netherlands: University of Twente.

Burt, R. S. (1992). Structural holes: The social structure of competition. Cambridge, MA: Harvard University Press.

Carr, J. B., Hawkins, C. V., \& Westberg, D. E. (2017). An exploration of collaboration risk in joint ventures: Perceptions of risk by local economic development officials. Economic Development Quarterly, 31, 210-227. https://doi.org/10.1177/0891242417710325

Cohen, W. M., \& Levinthal, D. A. (1990). Absorptive capacity: A new perspective on learning and innovation. Administrative Science Quarterly, 35(1), 128-153. https://doi. org $/ 10.2307 / 2393553$

Coleman, J. S. (1988). Social capital in the creation of human capital. American Journal of Sociology, 94, S95-S120. Retrieved from https://www.jstor.org/stable/2780243

Conrad, E. (2015). Bridging the hierarchical and collaborative divide: The role of network managers in scaling up a network approach to water governance in California. Policy \& Politics, 43, 349-366. https://doi.org/10.1332/030557315X14350819637950

Crona, B. I., \& Parker, J. N. (2012). Learning in support of governance: Theories, methods, and a framework to assess how bridging organizations contribute to adaptive resource governance. Ecology and Society, 17, Article 32. https://doi.org/10.5751/ES-04534-170132

Dunlop, C. A., \& Radaelli, C. M. (2018). The lessons of policy learning: Types, triggers, hindrances and pathologies. Policy \& Politics, 46, 255-272. https://doi.org/10.133 2/030557318X15230059735521

Feiock, R. C. (2007). Rational choice and regional governance. Journal of Urban Affairs, 29(1), 47-63. https://doi.org/10.1111/j.1467-9906.2007.00322.x

Feiock, R. C. (2009). Metropolitan governance and institutional collective action. Urban Affairs Review, 44, 356-377. https://doi.org/10.1177/1078087408324000

Feiock, R. C. (2013). The institutional collective action framework. Policy Studies Journal, 41, 397-425. https://doi.org/10.1111/psj.12023 
Feiock, R. C., Lubell, M., \& Lee, I. W. (2014). The political market framework and policy change (National Science Foundation Grant No. 0350799). Retrieved from https://localgov.fsu.edu/ sites/g/files/upcbnu1196/files/Politcal_Market_Policy_Change_2010_5_16_ML.pdf

Feiock, R. C., \& Scholz, J. T. (Eds.). (2010). Self-organizing federalism: Collaborative mechanisms to mitigate institutional collective action. New York, NY: Cambridge University Press.

Feiock, R. C., Steinacker, A., \& Park, H. J. (2009). Institutional collective action and economic development joint ventures. Public Administration Review, 69, 256-270. https://doi. org/10.1111/j.1540-6210.2008.01972.x

Gerber, E. R., Henry, A. D., \& Lubell, M. (2013). Political homophily and collaboration in regional planning networks. American Journal of Political Science, 57, 598-610. https://doi. org/10.1111/ajps.12011

Gerlak, A. K., \& Heikkila, T. (2011). Building a theory of learning in collaboratives: Evidence from the Everglades Restoration Program. Journal of Public Administration Research and Theory, 21, 619-644. https://doi.org/10.1093/jopart/muq089

Glückler, J., Suddaby, R., \& Lenz, R. (Eds.). (2018). Knowledge and institutions. Knowledge and Space: Vol. 13. Cham: Springer. https://doi.org/10.1007/978-3-319-75328-7

Hartley, J., \& Benington, J. (2006). Copy and paste, or graft and transplant? Knowledge sharing through inter-organizational networks. Public Money \& Management, 26(2), 101-108. https:// doi.org/10.1111/j.1467-9302.2006.00508.x

Hawkins, C. V. (2009). Prospects for and barriers to local government joint ventures. State and Local Government Review, 41(2), 108-119. https://doi.org/10.1177/0160323X0904100204

Hawkins, C. V., Hu, Q., \& Feiock, R. C. (2016). Self-organizing governance of local economic development: Informal policy networks and regional institutions. Journal of Urban Affairs, 38, 643-660. https://doi.org/10.1111/juaf.12280

Hawkins, C. V., Krause, R., Feiock, R. C., \& Curley, C. (2017). The administration and management of environmental sustainability initiatives: A collaborative perspective. Journal of Environmental Planning and Management, 61, 2015-2031. https://doi.org/10.1080/0964056 8.2017.1379959

Heikkila, T., \& Gerlak, A. K. (2013). Building a conceptual approach to collective learning: Lessons for public policy scholars. Policy Studies Journal, 41, 484-512. https://doi. org/10.1111/psj.12026

Hendrick, R. M., Jimenez, B. S., \& Lal, K. (2011). Does local government fragmentation reduce local spending? Urban Affairs Review, 47, 467-510. https://doi.org/10.1177/1078087411400379

Homsy, G. C., \& Warner, M. E. (2013). Climate change and the co-production of knowledge and policy in rural USA communities. Sociologia Ruralis, 53, 291-310. https://doi.org/10.1111/ soru. 12013

Huxham, C., \& Vangen, S. (2005). Managing to collaborate: The theory and practice of collaborative advantage. Abingdon: Routledge.

Jimenez, B. S. (2014). Externalities in the fragmented metropolis: Local institutional choices and the efficiency-equity trade-off. The American Review of Public Administration, 46, 314-336. https://doi.org/10.1177/0275074014550703

Koontz, T. M., Gupta, D., Mudliar, P., \& Ranjan, P. (2015). Adaptive institutions in socialecological systems governance: A synthesis framework. Environmental Science \& Policy, 53, 139-151. https://doi.org/10.1016/j.envsci.2015.01.003

Leach, W. D., Weible, C. M., Vince, S. R., Siddiki, S. N., \& Calanni, J. C. (2013). Fostering learning through collaboration: Knowledge acquisition and belief change in marine aquaculture partnerships. Journal of Public Administration Research and Theory, 24, 591-622. https://doi. org/10.1093/jopart/mut011

Lee, Y. (2016). From competition to collaboration: Intergovernmental economic development policy networks. Local Government Studies, 42, 171-188. https://doi.org/10.1080/0300393 0.2015 .1096267 
LeRoux, K., Brandenburger, P. W., \& Pandey, S. K. (2010). Interlocal service cooperation in US cities: A social network explanation. Public Administration Review, 70, 268-278. https://doi. org/10.1111/j.1540-6210.2010.02133.x

Lubell, M., Mewhirter, J. M., Berardo, R., \& Scholz, J. T. (2017). Transaction costs and the perceived effectiveness of complex institutional systems. Public Administration Review, 77, 668-680. https://doi.org/10.1111/puar.12622

March, J. G. (1991). Exploration and exploitation in organizational learning. Organization Science, 2(1), 71-87. https://doi.org/10.1287/orsc.2.1.71

March, J. G., \& Olsen, J. P. (1995). Democratic governance. New York: Free.

Maser, S. M. (1998). Constitutions as relational contracts: Explaining procedural safeguards in municipal charters. Journal of Public Administration Research and Theory, 8, 527-564. https:// doi.org/10.1093/oxfordjournals.jpart.a024395

McGinnis, M. D. (Ed.). (1999). Polycentricity and local public economies: Readings from the workshop in political theory and policy analysis. Ann Arbor, MI: University of Michigan Press. https://doi.org/10.3998/mpub.16061

Moore, M. H. (1995). Creating public value: Strategic management in government. Cambridge, MA: Harvard University Press.

Munsing, E., \& Lamb, C. J. (2011). Joint interagency task force-south: The best known, least understood interagency success. Institute for National Strategic Studies, Strategic Perspectives: Vol. 5. Washington, D.C.: National Defense University Press. Retrieved from https://ndupress. ndu.edu/Portals/68/Documents/stratperspective/inss/Strategic-Perspectives-5.pdf

Newig, J., Günther, D., \& Pahl-Wostl, C. (2010). Synapses in the network: Learning in governance networks in the context of environmental management. Ecology and Society, 15, Article 24. https://doi.org/10.5751/ES-03713-150424

Nooteboom, B. (2000). Learning by interaction: Absorptive capacity, cognitive distance and governance. Journal of Management and Governance, 4(1-2), 69-92. https://doi.org/10.102 3/A:1009941416749

Olson, M. (1965). Logic of collective action: Public goods and the theory of groups. Cambridge, MA: Harvard University Press.

Ostrom, E. (1990). Governing the commons: The evolution of institutions for collective action. Cambridge, UK: Cambridge University Press.

Ostrom, E. (2005). Understanding institutional diversity. Princeton, NJ: Princeton University Press.

Ostrom, E. (2010). Polycentric systems for coping with collective action and global environmental change. Global Environmental Change, 20, 550-557. https://doi.org/10.1016/j. gloenvcha.2010.07.004

Ostrom, V., Tiebout, C. M., \& Warren, R. (1961). The organization of government in metropolitan areas: A theoretical inquiry. American Political Science Review, 55, 831-842. https://doi. org/10.2307/1952530

Porter, D. R., \& Salvesen, D. A. (Eds.). (1995). Collaborative planning for wetlands and wildlife: Issues and examples. Washington, D.C.: Island.

Powell, W. W. (1998). Learning from collaboration: Knowledge and networks in the biotechnology and pharmaceutical industries. California Management Review, 40, 228-240. https://doi. org/10.2307/41165952

Powell, W. W., Koput, K. W., \& Smith-Doerr, L. (1996). Interorganizational collaboration and the locus of innovation: Networks of learning in biotechnology. Administrative Science Quarterly, 41(1), 116-145. https://doi.org/10.2307/2393988

Provan, K. G., \& Kenis, P. (2008). Modes of network governance: Structure, management, and effectiveness. Journal of Public Administration Research and Theory, 18, 229-252. https://doi. org/10.1093/jopart/mum015

Putnam, R. D., Leonardi, R., \& Nonetti, R. Y. (1993). Making democracy work: Civic traditions in modern Italy. Princeton, NJ: Princeton University Press. 
Sabatier, P. A. (1988). An advocacy coalition framework of policy change and the role of policy-oriented learning therein. Policy Sciences, 21(2), 129-168. https://doi.org/10.1007/ BF00136406

Salamon, L. M. (Ed.). (2002). The tools of government: A guide to the new governance. New York, NY: Oxford University Press.

Schneider, M. (1986). Fragmentation and the growth of local government. Public Choice, 48, 255-263. https://doi.org/10.1007/BF00051622

Scholz, J. T., Berardo, R., \& Kile, B. (2008). Do networks solve collective action problems? Credibility, search, and collaboration. The Journal of Politics, 70, 393-406. https://doi. org/10.1017/s0022381608080389

Senge, P. M. (1990). The fifth discipline: The art and practice of the learning organization. New York: Doubleday.

Shipan, C. R., \& Volden, C. (2008). The mechanisms of policy diffusion. American Journal of Political Science, 52, 840-857. https://doi.org/10.1111/j.1540-5907.2008.00346.x

Shrestha, M., Berardo, R., \& Feiock, R. (2014). Solving institutional collective action problems in multiplex networks. Complexity, Governance \& Networks, 1(1), 49-60. https://doi. org/10.7564/14-CGN7

Spekkink, W. A. H., \& Boons, F. A. A. (2016). The emergence of collaborations. Journal of Public Administration Research and Theory, 26, 613-630. https://doi.org/10.1093/jopart/muv030

Swann, W. L. (2017). Examining the impact of local collaborative tools on urban sustainability efforts: Does the managerial environment matter? The American Review of Public Administration, 47, 455-468. https://doi.org/10.1177/0275074015598576

Swann, W. L., \& Kim, S. Y. (2018). Practical prescriptions for governing fragmented governments. Policy \& Politics, 46, 273-292. https://doi.org/10.1332/030557318X15230058720979

Tamtik, M. (2016). Institutional change through policy learning: The case of the European Commission and research policy. Review of Policy Research, 33(1), 5-21. https://doi. org/10.1111/ropr.12156

Tavares, A. F., \& Feiock, R. C. (2017). Applying an institutional collective action framework to investigate intermunicipal cooperation in Europe. Perspectives on Public Management and Governance, 1(4), 299-316. https://doi.org/10.1093/ppmgov/gvx014

Terman, J. N., \& Feiock, R. C. (2016). The effect of formal and informal contracting mechanisms on implementation performance in the US federalist system. Local Government Studies, 42, 309-331. https://doi.org/10.1080/03003930.2015.1110522

Weber, E. P., \& Khademian, A. M. (2008). Wicked problems, knowledge challenges, and collaborative capacity builders in network settings. Public Administration Review, 68, 334-349. https://doi.org/10.1111/j.1540-6210.2007.00866.x

Willem, A., \& Buelens, M. (2007). Knowledge sharing in public sector organizations: The effect of organizational characteristics on interdepartmental knowledge sharing. Journal of Public Administration Research and Theory, 17, 581-606. https://doi.org/10.1093/jopart/mul021

Williamson, O. E. (1991). Comparative economic organization: The analysis of discrete structural alternatives. Administrative Science Quarterly, 36, 269-296. https://doi.org/10.2307/2393356

Yang, L. (2017). Collaborative knowledge-driven governance: Types and mechanisms of collaboration between science, social science, and local knowledge. Science and Public Policy, 45(1), 53-73. https://doi.org/10.1093/scipol/scx047

Zeemering, E. S. (2019). An agenda for comparing local governance and institutional collective action in Canada and the United States. Urban Affairs Review, 55, 858-886. https://doi. org/10.1177/1078087417738094

Zumbrun, J., Pérez, S., \& Harrup, A. (2018, April 24). Energy, a bright spot in NAFTA talks, bogged down by dispute over rule change [Article]. The Wall Street Journal (New York). Retrieved from https://www.wsj.com/articles/energy-a-bright-spot-in-nafta-talksbogged-down-by-dispute-over-rule-change-1524562201 
Open Access This chapter is licensed under the terms of the Creative Commons Attribution 4.0 International License (http://creativecommons.org/licenses/by/4.0/), which permits use, sharing, adaptation, distribution and reproduction in any medium or format, as long as you give appropriate credit to the original author(s) and the source, provide a link to the Creative Commons license and indicate if changes were made.

The images or other third party material in this chapter are included in the chapter's Creative Commons license, unless indicated otherwise in a credit line to the material. If material is not included in the chapter's Creative Commons license and your intended use is not permitted by statutory regulation or exceeds the permitted use, you will need to obtain permission directly from the copyright holder. 